Article

\title{
Formation of Metallic Glass Coatings by Detonation Spraying of a $\mathrm{Fe}_{66} \mathrm{Cr}_{10} \mathrm{Nb}_{5} \mathrm{~B}_{19}$ Powder
}

\author{
Ivanna D. Kuchumova ${ }^{1,2}$, Igor S. Batraev ${ }^{1}{ }^{1}$, Vladimir Yu. Ulianitsky ${ }^{1}$, \\ Alexandr A. Shtertser ${ }^{1}{ }^{\mathbb{D}}$, Konstantin B. Gerasimov ${ }^{3}$, Arina V. Ukhina ${ }^{3}$, Natalia V. Bulina ${ }^{3}{ }^{-0}$, \\ Ivan A. Bataev ${ }^{2}$, Guilherme Yuuki Koga ${ }^{4}$, Yaofeng Guo ${ }^{4}$, Walter José Botta ${ }^{4} \mathbb{D}$, Hidemi Kato ${ }^{5}$, \\ Takeshi Wada $^{5}$, Boris B. Bokhonov ${ }^{3}$, Dina V. Dudina ${ }^{1,2,3, * \mathbb{D}}$ and Alberto Moreira Jorge, Jr. ${ }^{4,6}$ (D) \\ 1 Lavrentyev Institute of Hydrodynamics (LIH) SB RAS, Lavrentyev Ave. 15, 630090 Novosibirsk, Russia \\ 2 Department of Mechanical Engineering and Technologies, Novosibirsk State Technical University, \\ K. Marx Ave. 20, 630073 Novosibirsk, Russia \\ 3 Institute of Solid State Chemistry and Mechanochemistry SB RAS, Kutateladze str. 18, \\ 630128 Novosibirsk, Russia \\ 4 Department of Materials Science and Engineering, Federal University of São Carlos, Via Washington Luiz, \\ km 235, SP 13565-905 São Carlos, Brazil \\ 5 Institute for Materials Research, Tohoku University, Aoba Ku, 2-1-1 Katahira, Sendai, 980-8577 Miyagi, Japan \\ 6 Grenoble Alpes University, CNRS, LEPMI and SIMAP, F-38000 Grenoble, France \\ * Correspondence: dina1807@gmail.com
}

Received: 11 July 2019; Accepted: 29 July 2019; Published: 31 July 2019

check for updates

\begin{abstract}
The present work was aimed to demonstrate the possibility of forming $\mathrm{Fe}_{66} \mathrm{Cr}_{10} \mathrm{Nb}_{5} \mathrm{~B}_{19}$ metallic glass coatings by detonation spraying and analyze the coating formation process. A partially amorphous $\mathrm{Fe}_{66} \mathrm{Cr}_{10} \mathrm{Nb}_{5} \mathrm{~B}_{19}$ powder with particles ranging from $45 \mu \mathrm{m}$ to $74 \mu \mathrm{m}$ in diameter was used to deposit coatings on stainless steel substrates. The deposition process was studied for different explosive charges (fractions of the barrel volume filled with an explosive mixture $\left(\mathrm{C}_{2} \mathrm{H}_{2}+1.1 \mathrm{O}_{2}\right)$ ). As the explosive charge was increased from $35 \%$ to $55 \%$, the content of the crystalline phase in the coatings, as determined from the $\mathrm{X}$-ray diffraction patterns, decreased. Coatings formed at explosive charges of $55-70 \%$ contained as little as $1 \mathrm{wt} . \%$ of the crystalline phase. In these coatings, nanocrystals in a metallic glass matrix were only rarely found; their presence was confined to some inter-splat boundaries. The particle velocities and temperatures at the exit of the barrel were calculated using a previously developed model. The particle temperatures increased as the explosive charge was increased from $35 \%$ to $70 \%$; the particle velocities passed through maxima. The coatings acquire an amorphous structure as the molten particles rapidly solidify on the substrate; cooling rates of the splats were estimated. The $\mathrm{Fe}_{66} \mathrm{Cr}_{10} \mathrm{Nb}_{5} \mathrm{~B}_{19}$ metallic glass coatings obtained at explosive changes of $55-60 \%$ showed low porosity $(0.5-2.5 \%)$, high hardness (715-1025 HV), and high bonding strength to the substrate (150 MPa).
\end{abstract}

Keywords: detonation spraying; coating; metallic glass; microstructure; bonding strength; microhardness

\section{Introduction}

In the past two decades, metallic glasses have received much attention from researchers and engineers due to their attractive mechanical properties, wear and corrosion resistance, and the ability to be thermoplastically processed in the super-cooled liquid region [1-3]. Metallic glasses are studied in the form of bulk materials [3], reinforcing phases in composites [4-7], and coatings [8].

Iron-based metallic glass coatings present viable solutions to protect surfaces from corrosion and increase their wear resistance [8-11]. Owing to reduced cost in comparison with other metallic 
glasses, Fe-based metallic glasses are of particular interest for practical applications. Several attempts to deposit Fe-based metallic glass coatings by the thermal spraying methods have been made [12-17]. The formation of metallic glass coatings by thermal spraying is a challenge, as, during the deposition, conditions should be created either to preserve an amorphous structure of the material (in the case of spraying of amorphous alloy powders) or to produce amorphous layers through melting of the particles and rapid solidification. The quality of coatings built by re-solidified particles is usually better compared with coatings formed by solid particles in terms of adhesion, cohesion, and porosity. During spraying, oxidation of the sprayed material should be prevented, as oxide particles formed in situ deteriorate the properties of the coatings and facilitate crystallization of the alloy acting as nucleation centers.

In detonation spraying, coatings are formed as the powder particles are heated and accelerated towards a substrate by the detonation products of gaseous mixtures. The coatings can form upon collision of solid, partially molten or fully molten particles with the substrate. In the detonation coatings obtained from a $\mathrm{Fe}_{48} \mathrm{Cr}_{15} \mathrm{Mo}_{14} \mathrm{C}_{15} \mathrm{~B}_{6} \mathrm{Y}_{2}$ fully amorphous alloy powder, the fraction of the amorphous phase was only $54 \%$ [16]. Despite partial crystallization, the ability of the coatings to resist localized corrosion allowed the authors to recommend them as surface protection for marine environments. Xie et al. [15] presented a comparative analysis of the microstructure and mechanical properties of $\mathrm{Fe}_{48} \mathrm{Mo}_{14} \mathrm{Cr}_{15} \mathrm{Y}_{2} \mathrm{C}_{15} \mathrm{~B}_{6}$ coatings obtained by detonation, plasma, and high-velocity oxygen fuel spraying. It was found that the detonation coatings possess the highest content of the amorphous phase among the studied coatings.

In the computer-controlled detonation spraying (CCDS) process developed at Lavrentyev Institute of Hydrodynamics, Siberian Branch of the Russian Academy of Sciences (LIH SB RAS) [18], the composition of the explosive gaseous mixture and its volume can be precisely controlled. As those parameters determine the thermal and chemical actions of the detonation products on the sprayed materials, the use of computer control of the process makes spraying results fully reproducible. It was shown that conditions of the splat formation during the deposition influence not only the microstructure of the coatings but also their phase composition, including the formation of metastable phases $[19,20]$. At present, in research laboratories, detonation spraying guns are still not as widespread as other thermal spray facilities. For this reason, studies of the deposition processes of amorphous alloy coatings by detonation spraying have been limited. The goal of the present work was to obtain $\mathrm{Fe}_{66} \mathrm{Cr}_{10} \mathrm{Nb}_{5} \mathrm{~B}_{19}$ metallic glass coatings by detonation spraying and analyze the coating formation process.

\section{Materials and Methods}

For making the master alloy, commercial purity metals and alloys were used as starting materials: Fe-B alloy (B content 16.54 wt.\%, ACL Metais, Araçariguama, Brazil), Fe-Nb alloy (Nb content $66.4 \mathrm{wt} . \%$, ACL Metais, Araçariguama, Brazil), metallic chromium (Cr content $>99.3 \mathrm{wt} . \%$, ACL Metais, Araçariguama, Brazil), and metallic iron (Fe content $>99.5$ wt.\%, Höganäs, Mogi das Cruzes, Brazil). The $\mathrm{Fe}_{66} \mathrm{Cr}_{10} \mathrm{Nb}_{5} \mathrm{~B}_{19}$ alloy powder was obtained by argon gas atomization using a HERMIGA 75/5VI gas atomizer (Phoenix Scientific Industries Ltd., Hailsham, East Sussex, UK). The 45-75 $\mu \mathrm{m}$ fraction was separated by sieving and used for the coating deposition.

Detonation spraying was carried out using a CCDS2000 facility developed at LIH SB RAS, Novosibirsk, Russia. The barrel of the gun consisted of two sections: a combustion chamber $(700 \mathrm{~mm}$ in length and $20 \mathrm{~mm}$ in diameter) and a muzzle section (300 $\mathrm{mm}$ in length and $16 \mathrm{~mm}$ in diameter). The design and advantages of barrel of this geometry are described in [21]. Spraying was conducted at an $\mathrm{O}_{2} / \mathrm{C}_{2} \mathrm{H}_{2}$ molar ratio of 1.1:1 and explosive charges (fractions of the barrel volume filled with the $\mathrm{C}_{2} \mathrm{H}_{2}+1.1 \mathrm{O}_{2}$ mixture) of $35-70 \%$. The powder injection point was located inside the barrel at a distance of $300 \mathrm{~mm}$ from the barrel open end. Nitrogen was used as a carrier gas to reduce the probability of oxidation of particles during the deposition process. Coatings were deposited at a rate of fire of the detonation gun of 2 shots per second. At this rate of fire, the consumption of the explosive mixture is about 200,300, and $400 \mathrm{~cm}^{3}$ per second for the explosive charges of $35 \%, 55 \%$, and 
$70 \%$, respectively. Detonation of $\mathrm{C}_{2} \mathrm{H}_{2}+1.1 \mathrm{O}_{2}$ explosive mixture is characterized by the following parameters: a detonation front velocity of $2894 \mathrm{~m} \mathrm{~s}^{-1}$, a pressure of $4.52 \mathrm{MPa}$, a temperature of the detonation products of $4533 \mathrm{~K}$, and a mass velocity behind the detonation front of $1300 \mathrm{~m} \mathrm{~s}^{-1}$ [18]. The coatings were deposited on stainless steel substrates at a stand-off distance of $200 \mathrm{~mm}$. Before spraying, sandblasting of the substrates was carried out for better adhesion of the coatings. Sandblasting was carried out by abrasive particles $300-600 \mu \mathrm{m}$ in size. The temperatures and velocities of the particles at the exit of the barrel were calculated using LIH software (LIH SB RAS, Novosibirsk. Russia) developed based on the analysis presented in [22].

The X-ray diffraction (XRD) phase analysis of the feedstock powder and detonation coatings was performed using a Bruker D8 ADVANCE diffractometer (Bruker AXS, Karlsruhe, Germany). The content of the amorphous phase in the coatings was determined by the Rietveld method using TOPAS 4.2 software (Bruker AXS, Karlsruhe, Germany).

The feedstock powder was investigated by differential scanning calorimetry (DSC) using a STA 449 F1 JUPITER thermal analysis instrument (Netzsch, Selb, Germany) in a flow of argon at a heating rate of $10^{\circ} \mathrm{min}^{-1}$. The $<45 \mu \mathrm{m}$ fraction of the gas atomized powder was used for determining the glass transition $\mathrm{T}_{\mathrm{g}}$ and crystallization temperatures $\mathrm{T}_{\mathrm{x}}$ of the $\mathrm{Fe}_{66} \mathrm{Cr}_{10} \mathrm{Nb}_{5} \mathrm{~B}_{19}$ metallic glass.

The density of the alloy was measured using an argon pycnometer (Institute of Solid State Chemistry and Mechanochemistry SB RAS, Novosibirsk, Russia).

The morphology and microstructure of the samples were studied by scanning electron microscopy using a TM-1000 Tabletop microscope (Hitachi, Tokyo, Japan), a Carl Zeiss EVO50 XVP (Oberkochen, Germany) microscope, and a Hitachi S-3400N (Tokyo, Japan) microscope. Energy-dispersive spectroscopy (EDS) was conducted using a NORAN Spectral System 7 (Thermo Fisher Scientific Inc., Waltham, MA, USA).

The fine structure of the coatings was observed by transmission electron microscopy (TEM) using an EM-002B microscope (TOPCON, Tokyo, Japan) working at $200 \mathrm{kV}$. Dimpling and ion milling was used to prepare samples for TEM studies.

The porosity of the coatings was measured using OLYMPUS Stream Image Analysis software Stream Essentials 1.9.1 (Tokyo, Japan). The optical images of the samples were obtained using an OLYMPUS GX-51 Optical Microscope (Tokyo, Japan).

Vickers microhardness of the coatings was measured on the polished cross-sections using a DuraScan 50 hardness tester (EMCO-TEST, Kuchl, Austria) at a load of $100 \mathrm{~g}$. The average values of microhardness were determined from 10 measurements.

The bonding strength of the coating was determined following ASTM C633-13 standard. The coating/substrate samples were fixed with Permabond ${ }^{\circledR}$ ES558 adhesive and subjected to tensile loading using a Zwick/Roell Z100 mechanical testing machine (Ulm, Germany). The bonding strength of the coatings was also determined by the pin test method, as described in [20]. The reported values of the bonding strength are averaged from five measurements. Standard deviation is also reported.

\section{Results and Discussion}

The morphology and microstructure of the $\mathrm{Fe}_{66} \mathrm{Cr}_{10} \mathrm{Nb}_{5} \mathrm{~B}_{19}$ feedstock powder are shown in Figure 1. The particles have a spherical or near-spherical shape. It can be seen that the majority of particles have satellites - particles of smaller sizes attached to their surface (Figure 1a), which is typical for the gas-atomized powders. As is seen in Figure 1b, the powder is partially crystalline. The dendritic structure is visible near the particle surface, indicating crystallization of the melt upon cooling. Figure 2 shows results of the EDS analysis of the powder confirming its elemental composition. 


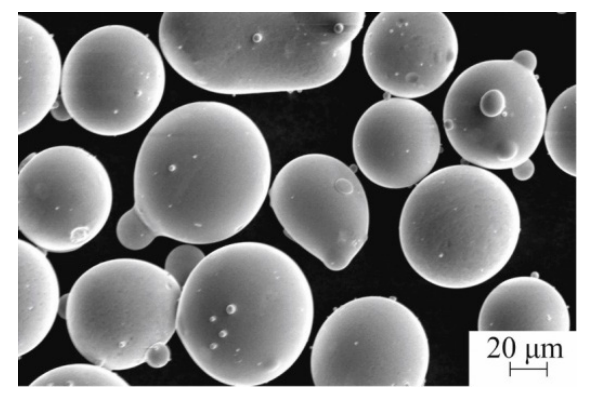

(a)

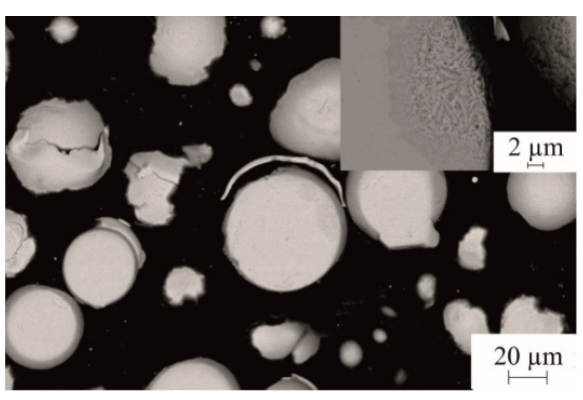

(b)

Figure 1. Scanning electron micrographs of the feedstock $\mathrm{Fe}_{66} \mathrm{Cr}_{10} \mathrm{Nb}_{5} \mathrm{~B}_{19}$ powder: (a) particle morphology; (b) particle microstructure.

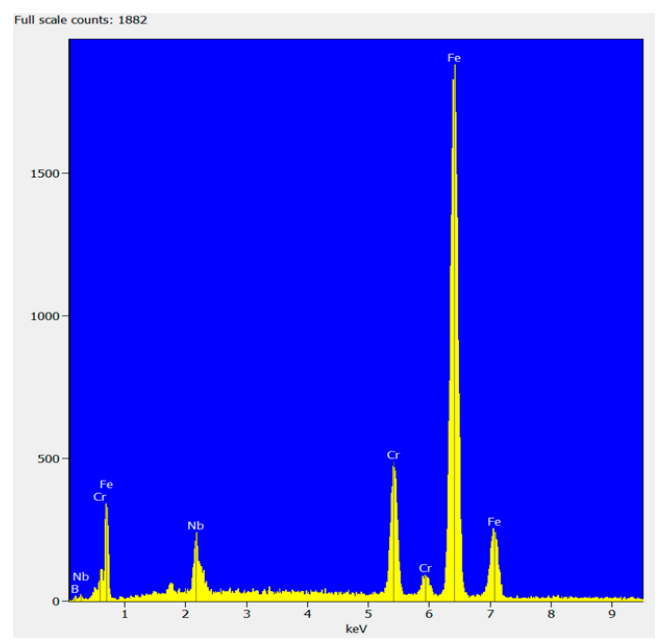

Figure 2. Energy-dispersive spectroscopy (EDS) of the $\mathrm{Fe}_{66} \mathrm{Cr}_{10} \mathrm{Nb}_{5} \mathrm{~B}_{19}$ feedstock powder.

The DSC profile of the feedstock powder indicates the presence of an amorphous phase: glass transition and crystallization take place upon heating (Figure 3). The solidus and liquidus temperature of the alloy were determined to be 1169 and $1287^{\circ} \mathrm{C}$, respectively. The XRD pattern of the $\mathrm{Fe}_{66} \mathrm{Cr}_{10} \mathrm{Nb}_{5} \mathrm{~B}_{19}$ feedstock powder is presented in Figure 4 . The pattern exhibits a broad halo between $40^{\circ}$ and $50^{\circ}$ $(2 \theta)$, indicating the presence of an amorphous phase. The crystalline phases contained in the powder are $\alpha$-Fe and $\mathrm{Fe}_{2} \mathrm{~B}$. In the present work, the gas-atomized powder particles $<45 \mu \mathrm{m}$ in size were fully amorphous (according to the XRD analysis), while those 45-75 $\mu \mathrm{m}$ in size were partially crystalline. The $\mathrm{T}_{\mathrm{g}}$ and $\mathrm{T}_{\mathrm{x}}$ of the $\mathrm{Fe}_{66} \mathrm{Cr}_{10} \mathrm{Nb}_{5} \mathrm{~B}_{19}$ metallic glass were determined by the DSC analysis of the particles $<45 \mu \mathrm{m}$ in size: $\mathrm{T}_{\mathrm{g}}=521{ }^{\circ} \mathrm{C} ; \mathrm{T}_{\mathrm{x}}=573{ }^{\circ} \mathrm{C}$.

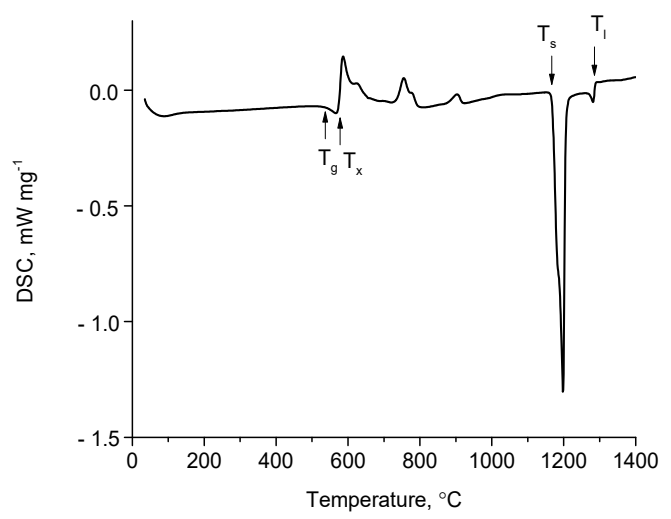

Figure 3. Differential scanning calorimetry (DSC) curve of the $\mathrm{Fe}_{66} \mathrm{Cr}_{10} \mathrm{Nb}_{5} \mathrm{~B}_{19}$ feedstock powder (45-75 $\mu \mathrm{m}$ ). 


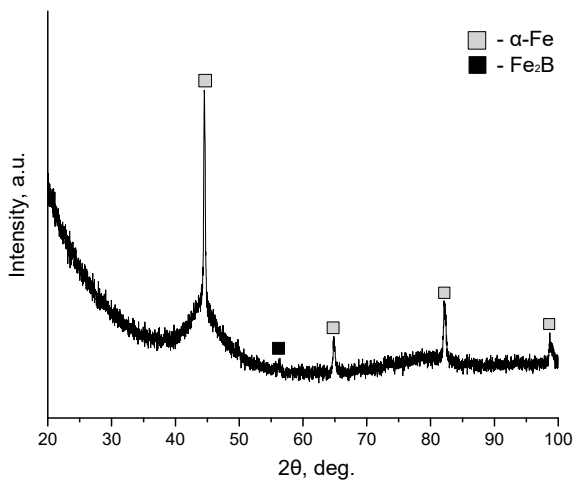

Figure 4. X-ray diffraction (XRD) pattern of the $\mathrm{Fe}_{66} \mathrm{Cr}_{10} \mathrm{Nb}_{5} \mathrm{~B}_{19}$ feedstock powder $(45-75 \mu \mathrm{m})$.

The XRD patterns of the detonation coatings are shown in Figure 5. A common feature of the patterns is the presence of a broad diffraction halo between $40^{\circ}$ and $50^{\circ}(2 \theta)$ indicating the presence of an amorphous phase. The content of the crystalline phase in the coatings estimated from the XRD patterns is given in Table 1 . Coatings formed at explosive charges of $55-70 \%$ contain as little as $1 \mathrm{wt} . \%$ of the crystalline phase. At an $\mathrm{O}_{2} / \mathrm{C}_{2} \mathrm{H}_{2}$ molar ratio of 1.1:1, the detonation products have a reducing character containing $58 \%$ of carbon monoxide $\mathrm{CO}$ and $22 \%$ of atomic hydrogen [23]. Under these conditions, no oxidation of the sprayed particles can take place [23]. The absence of extensive oxidation of the sprayed material is believed to be crucial for the formation of metallic glass coatings.

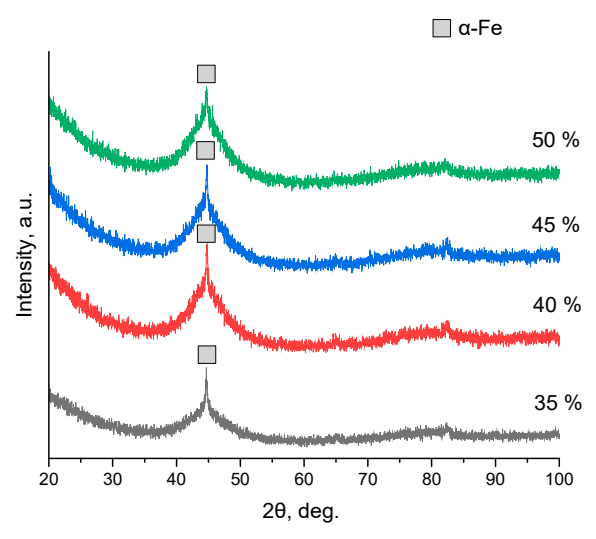

(a)

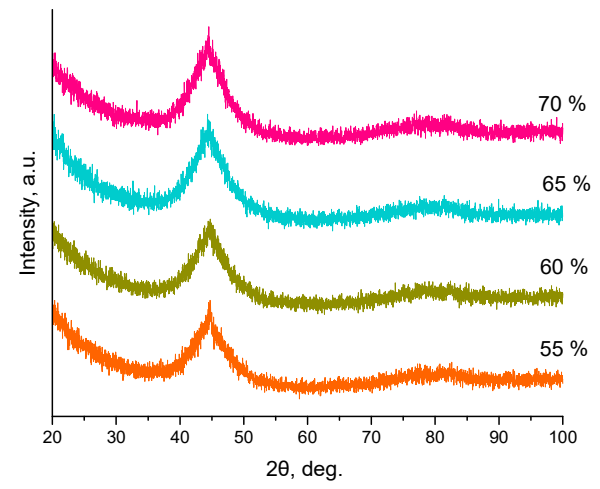

(b)

Figure 5. XRD patterns of the $\mathrm{Fe}_{66} \mathrm{Cr}_{10} \mathrm{Nb}_{5} \mathrm{~B}_{19}$ detonation coatings obtained at different explosive charges.

Table 1. Content of the crystalline phase, porosity, and Vickers microhardness of the $\mathrm{Fe}_{66} \mathrm{Cr}_{10} \mathrm{Nb}_{5} \mathrm{~B}_{19}$ detonation coatings. For the content of the crystalline phase and porosity, the standard deviations are given. For Vickers microhardness, the confidence intervals are given (for a confidence level of 0.95).

\begin{tabular}{cccc}
\hline Explosive Charge, \% & $\begin{array}{c}\text { Content of the } \\
\text { Crystalline Phase, wt.\% }\end{array}$ & Porosity, \% & $\begin{array}{c}\text { Vickers Microhardness, } \\
\text { HV }_{\mathbf{1 0 0}}\end{array}$ \\
\hline 35 & $5 \pm 0.2$ & $4.0 \pm 1.0$ & $540 \pm 210$ \\
40 & $4 \pm 0.2$ & $3.0 \pm 0.8$ & $750 \pm 55$ \\
45 & $3 \pm 0.2$ & $2.5 \pm 1.0$ & $780 \pm 145$ \\
50 & $2 \pm 0.2$ & $2.5 \pm 0.5$ & $875 \pm 130$ \\
55 & $1 \pm 0.2$ & $1.0 \pm 0.5$ & $920 \pm 95$ \\
60 & $1 \pm 0.2$ & $2.0 \pm 0.5$ & $870 \pm 155$ \\
75 & $1 \pm 0.2$ & $1.2 \pm 0.5$ & $770 \pm 100$ \\
70 & $1 \pm 0.2$ & $2.5 \pm 0.5$ & $770 \pm 75$ \\
\hline
\end{tabular}

Figure 6 shows cross-sections of the detonation coatings. It can be seen that the coatings possess a lamellar structure typical of thermally sprayed coatings formed from molten or semi-molten particles. 
As the explosive charge is increased from $35 \%$ to $60 \%$, fewer defects (pores, non-melted particles, and cracks) are observed in the microstructure of the coatings.

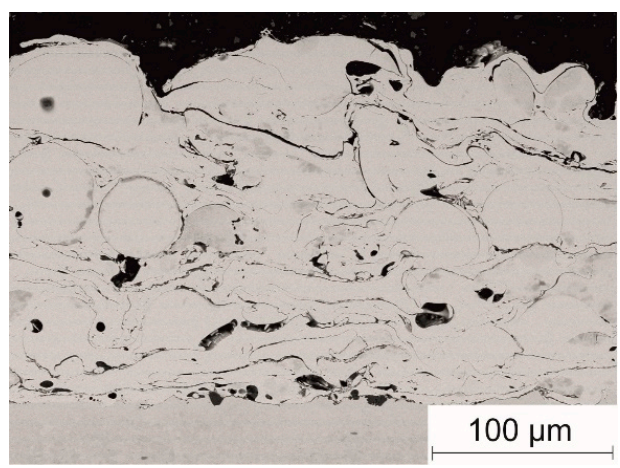

(a)

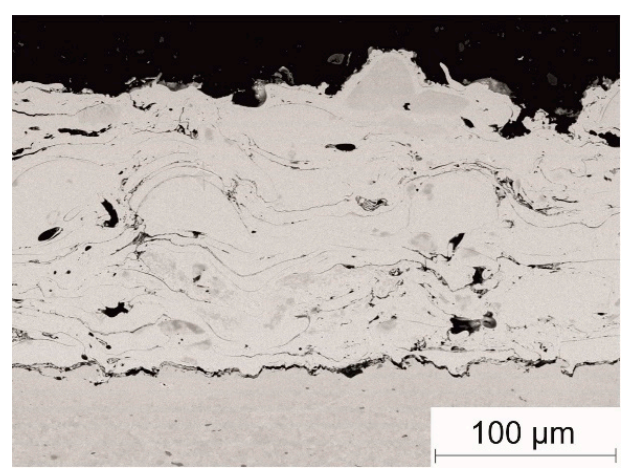

(c)



(e)

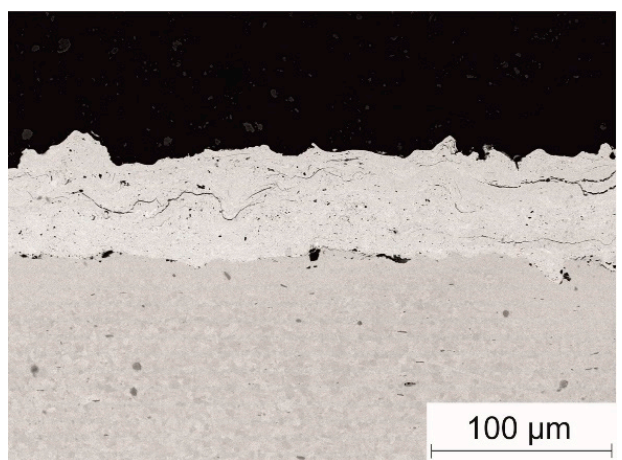

(g)



(b)

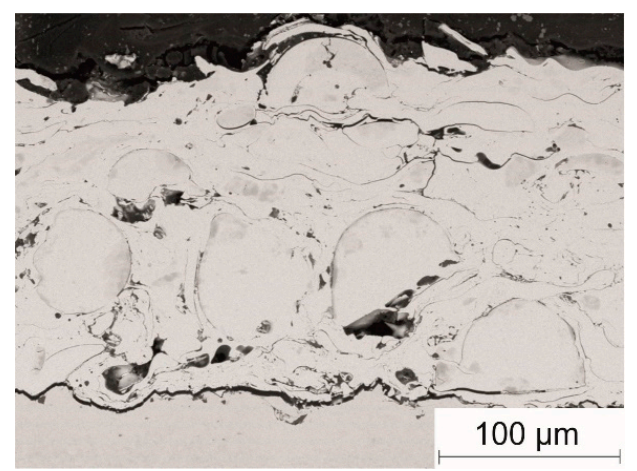

(d)

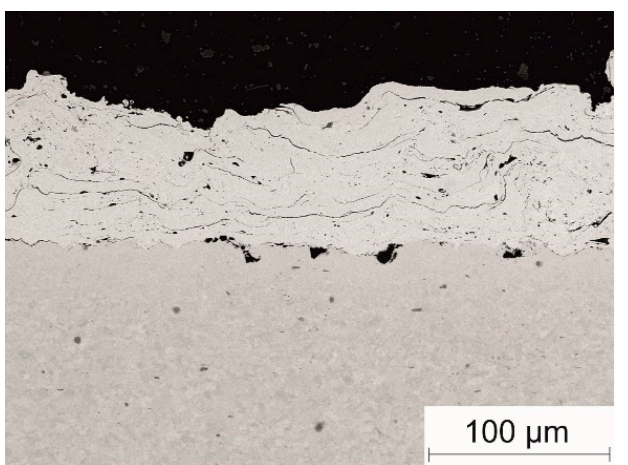

(f)

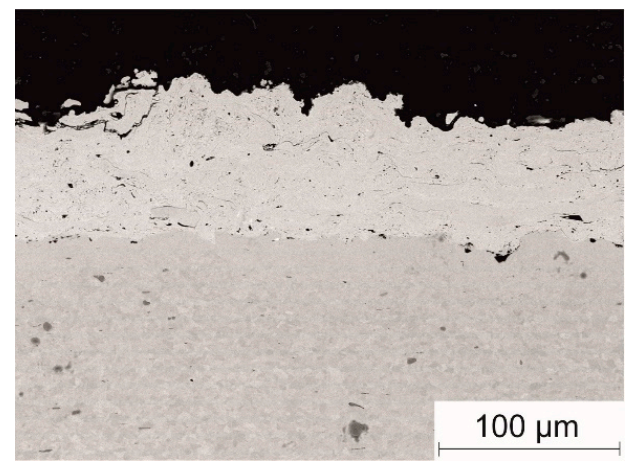

(h)

Figure 6. Cross-sections of the $\mathrm{Fe}_{66} \mathrm{Cr}_{10} \mathrm{Nb}_{5} \mathrm{~B}_{19}$ detonation coatings obtained at different explosive charges: (a) $35 \%$; (b) $40 \%$; (c) 45\%; (d) 50\%, (e) 55\%; (f) 60\%; (g) 65\%; (h) 70\%. 
A TEM bright-field image of the substrate/coating sample obtained at an explosive charge of $60 \%$ (Figure 7a) shows that an amorphous layer has a well-developed interface with the substrate. Selected-area electron diffraction patterns (SAEDP) confirm the crystalline nature of the substrate and the amorphous nature of the coating. A high-resolution image of the coating (Figure $7 \mathrm{~b}$ ) and a corresponding fast Fourier transform (inset in Figure $7 \mathrm{~b}$ ) provides convincing evidence of the amorphous structure. Only rarely were nanocrystals found in an amorphous matrix (at some inter-splat boundaries, Figure 8a). The chemical composition of the nanocrystals corresponds to the as-sprayed alloy, as is seen in Figure $8 b$.

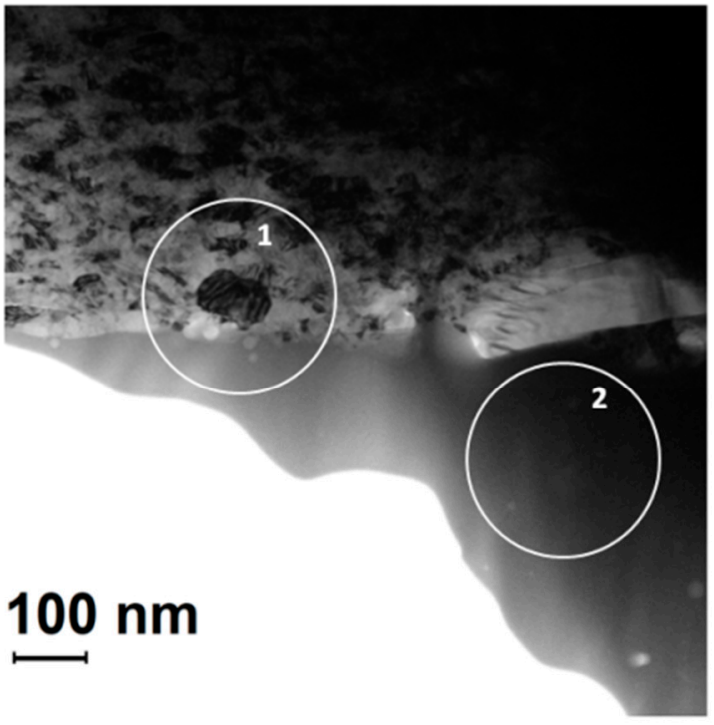

(a)



(b)

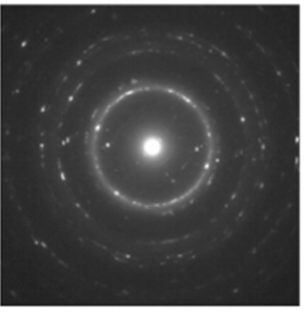

1

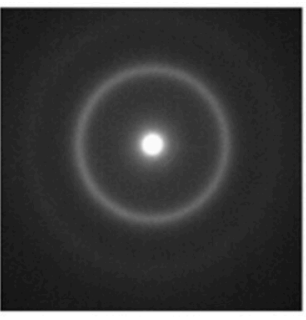

2 


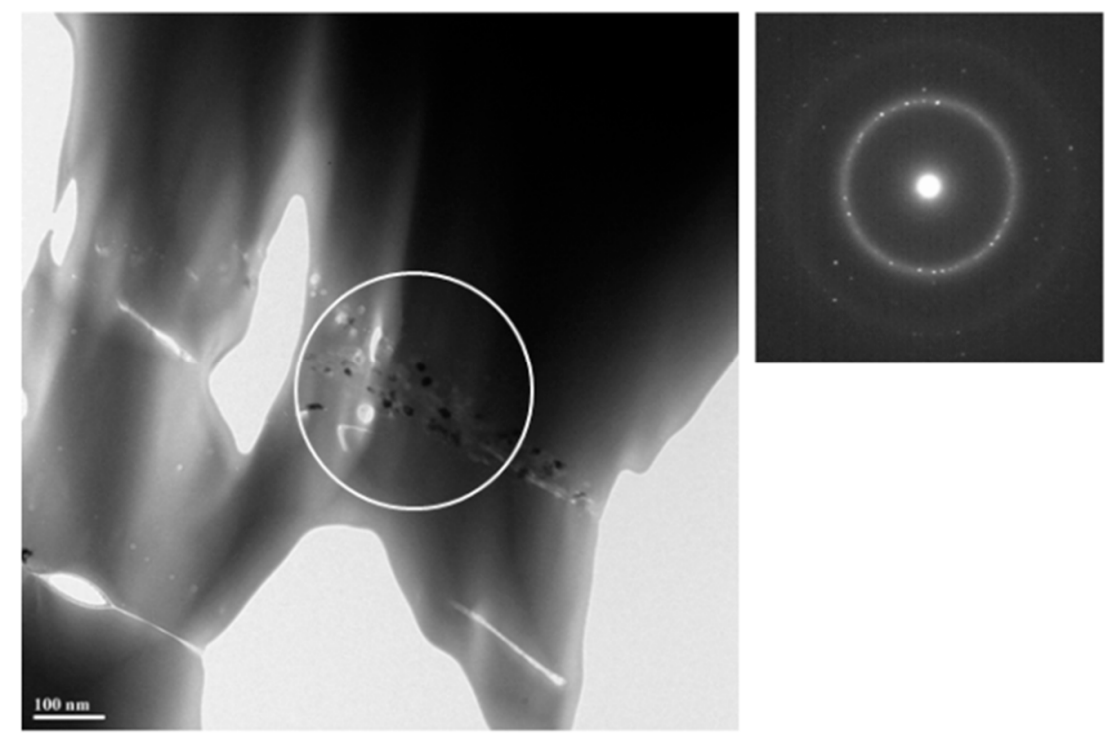

(a)

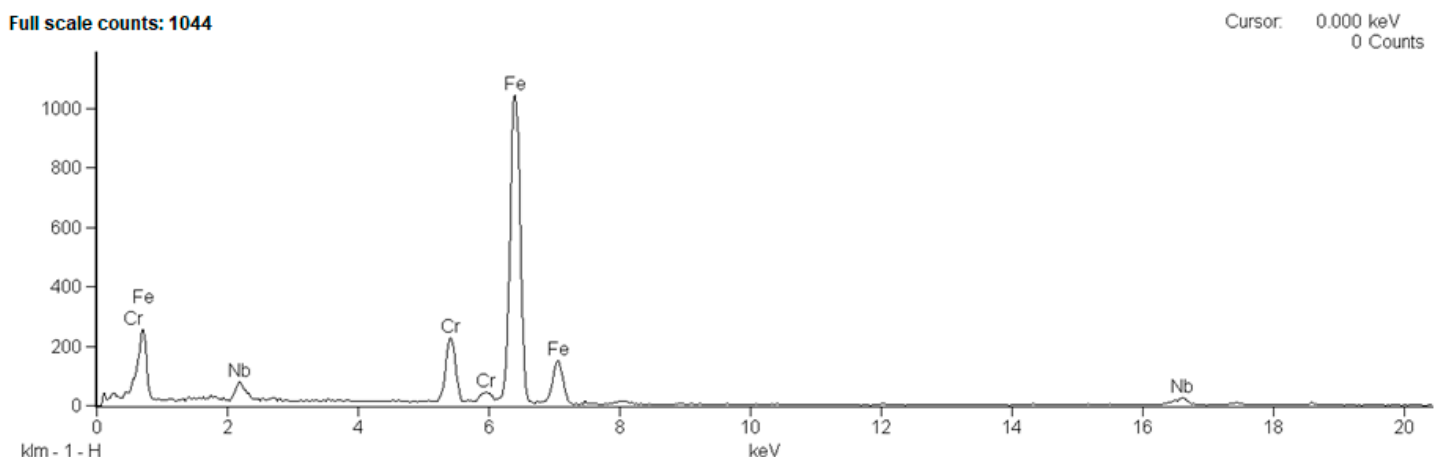

(b)

Figure 8. TEM image of the detonation coating structure showing nanocrystals found occasionally at the inter-splat boundaries and a corresponding SAEDP (a), elemental analysis results of the nanocrystals (b). Explosive charge 60\%.

The temperatures and velocities of the particles leaving the gun barrel calculated for different explosive charges and three particle sizes are presented in Figure 9. Simplification has been made during the calculations: it was assumed that the material melts at $1442 \mathrm{~K}$ (horizontal sections of curves in Figure 9a). For obtaining a lower bound of the temperature of the particles reaching the substrate and assessing the coating formation conditions, this simplification is acceptable. After exiting the barrel, the particles experience additional heating as they continue to be surrounded by the cloud of the detonation products. Calculations show that, at an explosive charge of $45 \%$, particles $45 \mu \mathrm{m}$ in diameter experience melting upon leaving the barrel (Figure 9a). When an explosive charge of $60 \%$ is used, even particles $75 \mu \mathrm{m}$ in diameter are heated up to $1442 \mathrm{~K}$. The calculated particle temperatures are consistent with results of the structural investigations of the coatings (Figure 6e,f): at explosive charges of $55-60 \%$, the coatings are formed mainly by solidification of the molten splats. 


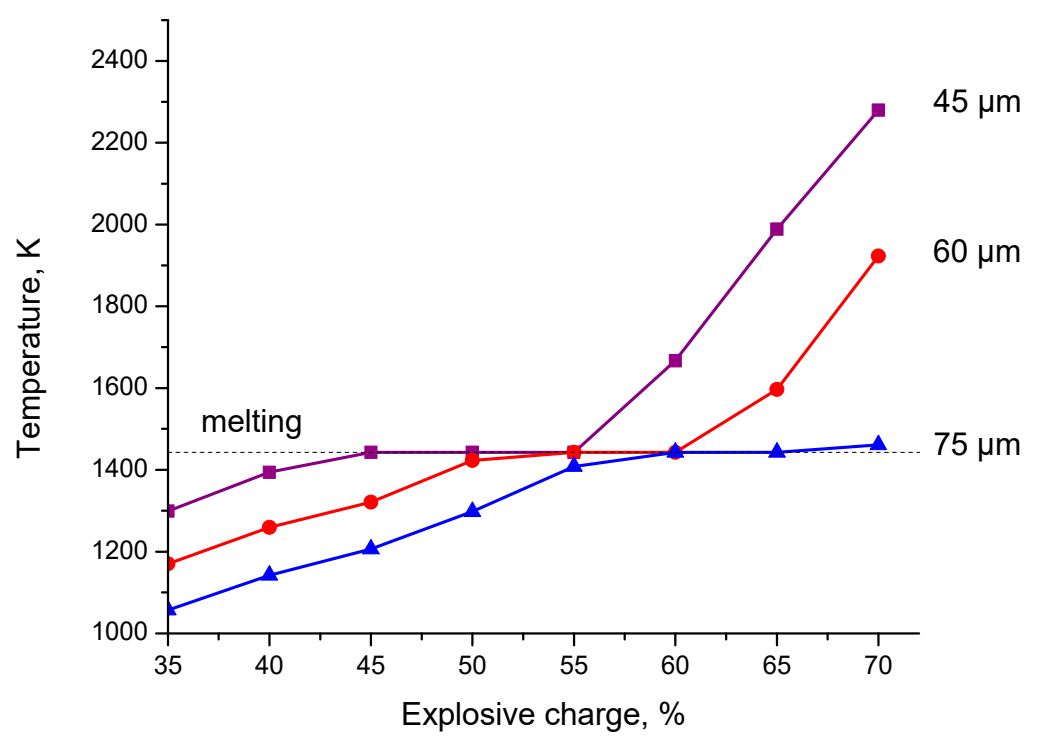

(a)



(b)

Figure 9. Calculated temperatures (a) and velocities (b) of $\mathrm{Fe}_{66} \mathrm{Cr}_{10} \mathrm{Nb}_{5} \mathrm{~B}_{19}$ particles as functions of explosive charge. Calculations were conducted for particles 45,60 , and $75 \mu \mathrm{m}$ in diameter. It was assumed that the material melts at $1442 \mathrm{~K}$ (horizontal sections of the curves in (a)).

The velocities of the particles pass through maxima as the explosive charge is increased from $35 \%$ to $70 \%$ (Figure $9 \mathrm{~b}$ ). The location of the powder injection point on the barrel determines the explosive charge, at which the maximum velocity is reached [24]. Low particle velocities at large explosive charges may cause deterioration of the coating quality (uniformity and contiguity).

According to [25], during argon gas atomization, Fe alloy particles $50 \mu \mathrm{m}$ in size cool down at an average rate of $10^{5} \mathrm{~K} \mathrm{~s}^{-1}$. As mentioned above, the gas-atomized powder particles $<45 \mu \mathrm{m}$ in size obtained in the present work are fully amorphous. Consequently, for the metallic glass coatings to be formed, cooling rates higher than $10^{5} \mathrm{~K} \mathrm{~s}^{-1}$ should be provided for the detonation splats. The cooling rate of the splats can be estimated using the characteristic cooling time defined as $t=\frac{h^{2}}{a}$, where $h$ is 
the thickness of the splat (can be taken equal to $15 \mu \mathrm{m}$ for particles $45 \mu \mathrm{m}$ in diameter) and $a$ is the thermal diffusivity of the material, $a=\frac{k}{\rho c_{p}}$ ( $k$ is the thermal conductivity, $\rho$ is the density; $c_{p}$ is the heat capacity) [26]. For calculations, $k=10 \mathrm{~W} \mathrm{~m}^{-1} \mathrm{~K}^{-1}$ and $c_{p}=1 \mathrm{~kJ} \mathrm{~kg}^{-1} \mathrm{~K}^{-1}$ were used. The measured density of the alloy is $7580 \mathrm{~kg} \mathrm{~m}^{-3}$. If, within the characteristic cooling time, a temperature drop from the liquidus temperature of $1560 \mathrm{~K}$ to $760 \mathrm{~K}$ is assumed, a cooling rate of the order of $10^{6} \mathrm{~K} \mathrm{~s}^{-1}$ is obtained. This cooling rate is high enough to ensure the formation of metallic glass coatings. Thinner splats cool at even higher rates.

The porosity and microhardness of the detonation coatings are given in Table 1. Coatings obtained at explosive charges of $55 \%$ and $60 \%$ show low porosity $(0.5-2.5 \%)$. The microhardness of these coatings is in the 715-1025 HV range. These values of microhardness are encountered in some Fe-based bulk metallic glasses [27]. As the explosive charge is increased from $35 \%$ to $55 \%$, the porosity of the coatings decreases, while their microhardness increases. This can be explained by the increase in the temperature of the particles and the fraction of the material experiencing melting (Figure 9a). The degree of consolidation of particles (cohesion) also increases. Explosive charges of 55-60\% can be recommended for producing $\mathrm{Fe}_{66} \mathrm{Cr}_{10} \mathrm{Nb}_{5} \mathrm{~B}_{19}$ metallic glass coatings with low porosity and high hardness by detonation spraying.

The bonding strength of the coatings was determined using samples obtained at an explosive charge of $55 \%$. The bonding strength of the coatings determined according to ASTM C633-13 standard was found to be higher than $76 \mathrm{MPa}$, which is the tensile strength of Permabond ES 558; the specimen rupture occurred through the polymer layer. The bonding strength measured by the pin test method was $150 \pm 10 \mathrm{MPa}$. The fracture surface (the surface of the pin) is shown in Figure 10. It can be seen that rupture occurred along the coating/substrate interface. The obtained bonding strength values are higher than those typically found in metallic coatings obtained by detonation spraying [20].

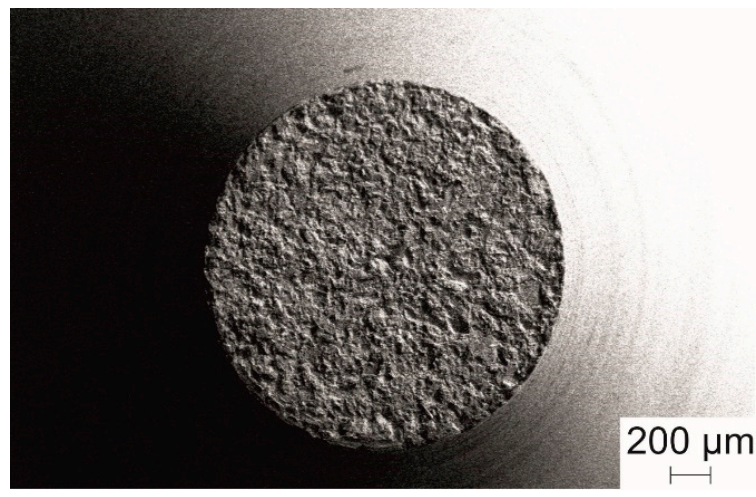

(a)

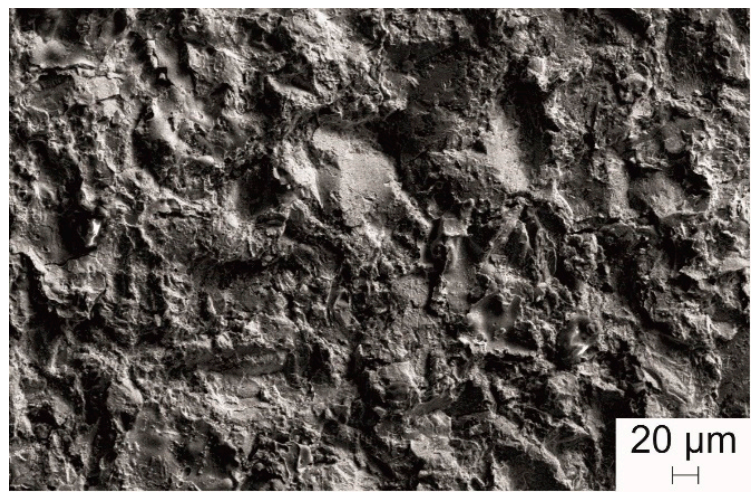

(b)

Figure 10. General view of the flat end of the pin after the bonding strength test (a); morphology of the pin surface indicating rupture along the coating/substrate interface (b).

\section{Conclusions}

A possibility of forming $\mathrm{Fe}_{66} \mathrm{Cr}_{10} \mathrm{Nb}_{5} \mathrm{~B}_{19}$ metallic glass coatings by detonation spraying of a gas-atomized powder was demonstrated. Thanks to the pulse nature of the detonation spraying process, the temperature of the particles depositing on the substrate can be adjusted by changing the time between the shots. Conditions of rapid cooling of the splats can thus be met. Although the $\mathrm{Fe}_{66} \mathrm{Cr}_{10} \mathrm{Nb}_{5} \mathrm{~B}_{19}$ feedstock powder was partially crystalline, coatings with an amorphous structure formed, which was due to melting of the particles and rapid solidification of the splats. The amorphous structure of the coatings was confirmed by XRD and TEM. Nanocrystals in the metallic glass matrix were only rarely found (at inter-splat boundaries). The glassy $\mathrm{Fe}_{66} \mathrm{Cr}_{10} \mathrm{Nb}_{5} \mathrm{~B}_{19}$ coatings exhibit hardness comparable to that of some bulk Fe-based metallic glasses and extremely high bonding strength to a stainless steel substrate. 
Author Contributions: Conceptualization, D.V.D., I.A.B. and A.M.J.J.; methodology, I.S.B., W.J.B., A.A.S. and V.Y.U.; investigation, I.D.K., B.B.B., N.V.B., A.V.U., K.B.G., Y.G. and G.Y.K.; writing- original draft preparation, I.D.K. and I.S.B.; writing-review and editing, D.V.D., B.B.B., H.K., T.W. and A.M.J.J.; supervision, D.V.D.; project administration, V.Y.U. and A.M.J.J.; funding acquisition, D.V.D., I.D.K., I.S.B., A.A.S. and V.Y.U.

Funding: I.D.K. and I.S.B. acknowledge partial support by the Russian Foundation for Basic Research and the Novosibirsk region, project 19-43-543034 r_mol_a.

Acknowledgments: TEM studies were conducted within the Global Institute for Materials Research Tohoku program (proposal 18GK0003), IMR Tohoku University, Japan. The authors are grateful to Shun Ito (Tohoku University) for his help in conducting TEM investigations and Konstantin A. Tsarakhov (LIH SB RAS) for technical assistance.

Conflicts of Interest: The authors declare no conflicts of interest.

\section{References}

1. Greer, A.L. Metallic glasses on the threshold. Mater. Today 2009, 12, 14-22. [CrossRef]

2. Inoue, A.; Takeuchi, A. Recent development and application products of bulk glassy alloys. Acta Mater. 2011, 59, 2243-2267. [CrossRef]

3. Inoue, A. Bulk glassy alloys: Historical development and current research. Engineering 2015, 1, $185-191$. [CrossRef]

4. Wang, Z.; Scudino, S.; Stoica, M.; Zhang, W.W.; Eckert, J. Al-based matrix composites reinforced with short Fe-based metallic glassy fiber. J. Alloy Compd. 2015, 651, 170-175. [CrossRef]

5. Wang, Z.; Georgarakis, K.; Nakayama, K.; Li, Y.; Tsarkov, A.; Xie, G.; Dudina, D.; Louzguine, D.; Yavari, A.R. Microstructure and mechanical behavior of metallic glass fiber-reinforced $\mathrm{Al}$ alloy matrix composites. Sci. Rep. 2016, 6, 24384. [CrossRef] [PubMed]

6. Zhang, W.W.; Hu, Y.; Wang, Z.; Yang, C.; Zhang, G.Q.; Prashanth, K.G.; Suryanarayana, C. A novel high-strength Al-based nanocomposite reinforced with Ti-based metallic glass nanoparticles produced by powder metallurgy. Mater. Sci. Eng. A 2018, 734, 34-41. [CrossRef]

7. Dudina, D.V.; Georgarakis, K.; Li, Y.; Aljerf, M.; Braccini, M.; Yavari, A.R.; Inoue, A. Cu-based metallic glass particle additions to significantly improve overall compressive properties of an $\mathrm{Al}$ alloy. Compos. Part A 2010, 41, 1551-1557. [CrossRef]

8. Liu, L.; Zhang, C. Fe-based amorphous coatings: Structures and properties. Thin Solid Film 2014, 561, 70-86. [CrossRef]

9. Gu, X.J.; Poon, S.J.; Shiflet, G.J. Mechanical properties of iron-based bulk metallic glasses. J. Mater. Res. 2007, 22, 344-351. [CrossRef]

10. Yang, Y.; Zhang, C.; Peng, Y.; Yu, Y.; Liu, L. Effects of crystallization on the corrosion resistance of Fe-based amorphous coatings. Corros. Sci. 2012, 59, 10-19. [CrossRef]

11. Pang, S.J.; Zhang, T.; Asami, K.; Inoue, A. Synthesis of Fe-Cr-Mo-C-B-P bulk metallic glasses with high corrosion resistance. Acta Mater. 2002, 50, 489-497. [CrossRef]

12. Zhang, H.; Xie, Y.; Huang, L.; Huang, S.; Zheng, X.; Chen, G. Effect of feedstock particle sizes on wear resistance of plasma sprayed Fe-based amorphous coatings. Surf. Coat. Technol. 2014, 258, 495-502. [CrossRef]

13. Zhou, Y.; Ma, G.; Wang, H.; Li, G.; Chen, S.; Wang, H.; Liu, M. Fabrication and characterization of supersonic plasma sprayed Fe-based amorphous metallic coatings. Mater. Des. 2016, 110, 332-339. [CrossRef]

14. Xie, L.; Wang, Y.; Xiong, X.; Chen, Z.; Wang, Y. Effects of oxygen fuel rate on microstructure and wear properties of detonation sprayed iron-based amorphous coatings. Mater. Trans. 2018, 59, 1867-1871. [CrossRef]

15. Xie, L.; Wang, Y.; Xiong, X.; Chen, Z. Comparison of microstructure and tribological properties of plasma, high velocity oxy-fuel and detonation sprayed coatings from an iron-based powder. Mater. Trans. 2018, 59, 1591-1595. [CrossRef]

16. Zhou, Z.; Wang, L.; Wang, F.; Liu, Y. Formation and corrosion behavior of Fe-based amorphous metallic coatings prepared by detonation gun spraying. Trans. Nonferr. Met. Soc. China 2009, 19, s634-s638. [CrossRef]

17. Guo, Y.; Koga, G.Y.; Moreira Jorge, A., Jr.; Savoie, S.; Schulz, R.; Kiminami, C.S.; Bolfarini, C.; Botta, W.J. Microstructural investigation of Fe-Cr-Nb-B amorphous/nanocrystalline coating produced by HVOF. Mater. Des. 2016, 111, 608-615. [CrossRef] 
18. Ulianitsky, V.; Shtertser, A.; Zlobin, S.; Smurov, I. Computer-controlled detonation spraying: From process fundamentals toward advanced applications. J. Therm. Spray Technol. 2011, 20, 791-801. [CrossRef]

19. Ulianitsky, V.Y.; Dudina, D.V.; Batraev, I.S.; Rybin, D.K.; Bulina, N.V.; Ukhina, A.V.; Bokhonov, B.B. The influence of the in-situ formed and added carbon on the formation of metastable Ni-based phases during detonation spraying. Mater. Lett. 2016, 181, 127-131. [CrossRef]

20. Ulianitsky, V.Y.; Batraev, I.S.; Shtertser, A.A.; Dudina, D.V.; Bulina, N.V.; Smurov, I. Detonation spraying behaviour of refractory metals: Case studies for Mo and Ta-based powders. Adv. Powder Technol. 2018, 29, 1859-1864. [CrossRef]

21. Batraev, I.S.; Prokhorov, E.S.; Ul'yanitskii, V.Y. Acceleration and heating of powder particle by gas detonation products in channels with a conical passage. Comb. Explos. Shock Waves 2014, 50, 315-322. [CrossRef]

22. Gavrilenko, T.P.; Nikolaev, Y.A. Calculation of detonation gas spraying. Comb. Explos. Shock Waves 2007, 43, 724-731. [CrossRef]

23. Dudina, D.V.; Batraev, I.S.; Ulianitsky, V.Y.; Korchagin, M.A. Possibilities of the Computer-Controlled Detonation Spraying method: A chemistry viewpoint. Ceram. Int. 2014, 40, 3253-3260. [CrossRef]

24. Batraev, I.S.; Ulianitsky, V.Y.; Dudina, D.V. Detonation spraying of copper: Theoretical analysis and experimental studies. Mater. Today Proc. 2017, 4, 11346-11350. [CrossRef]

25. Golod, V.M.; Sufiiarov, V.S. The evolution of structural and chemical heterogeneity during rapid solidification at gas atomization. IOP Conf. Ser. Mater. Sci. Eng. 2017, 192, 012009. [CrossRef]

26. Gavrilenko, T.P.; Nikolaev, Y.A.; Prokhorov, E.S.; Ul'yanitskii, V.Y. Mechanisms of coating formation with flame spraying. Comb. Explos. Shock Waves 1990, 26, 228-238. [CrossRef]

27. Li, H.X.; Lu, Z.C.; Wang, S.L.; Wu, Y.; Lu, Z.P. Fe-based bulk metallic glasses: Glass formation, fabrication, properties and applications. Prog. Mater. Sci. 2019, 103, 235-318. [CrossRef]

(C) 2019 by the authors. Licensee MDPI, Basel, Switzerland. This article is an open access article distributed under the terms and conditions of the Creative Commons Attribution (CC BY) license (http://creativecommons.org/licenses/by/4.0/). 